\title{
MULTIDISCIPLINARY MANAGEMENT OF A PATIENT WITH HYPODONTIA AND TRANSPOSED MANDIBULAR CANINES: A CASE REPORT
}

\author{
Dr. Pramod Joshi, ${ }^{1}$ Dr. Nilesh Hegde, ${ }^{2}$ Dr. Sudhakar Bhat ${ }^{3}$ \\ 1. Prosthodontist, Nepal Police Hospital, Kathmandu \\ 2. Former PG student, Dept of Orthodontics, Manipal College of Dental Sciences, Mangalore, India \\ 3. Professor, Vyas Dental College and Hospital, Jodhpur, India
}

Correspondence : pramodrajjoshi@yahoo.com

\section{ABSTRACT}

A multidisciplinary approach is generally required in the treatment of patients who presents with missing and malpositioned teeth to achieve a long term esthetic and functional result. Treatment of a patient with hypodontia and congenitally transposed mandibular canines using a multidisciplinary approach is presented.

Key Words: hypodontia, management, multidisciplinary, tooth transposition

\section{INTRODUCTION:}

Disturbances during the early stages of tooth formation may result in the developmental or congenital absence of one or more teeth. Generally the absence of one to six teeth is termed hypodontia. ${ }^{1,2}$ Hypodontia is more common in the permanent dentition, occurring in about $2 \%-10 \%$ in different populations (excluding absent third molars) compared to the primary dentition where the prevalence is $<1 \%$. It is more common in females and there are also racial differences. For example, the prevalence of missing mandibular permanent central incisors is much more common in Japanese and Swedish populations than in other groups studied. One of the widely accepted sequences of missing teeth is: Mandibular second premolar > Maxillary lateral incisor $>$ Maxillary second premolar > Mandibular incisors. ${ }^{2}$ Although the genetic basis of hypodontia is not yet understood, several regulatory genes involved in tooth development have been identified and it is likely that mutations in these result in tooth agenesis. ${ }^{3}$

Tooth transposition is defined as a unique and extreme form of ectopic eruption in which a permanent tooth develops and erupts in the position normally occupied by another permanent tooth. ${ }^{4}$ Other dental anomalies, such as congenitally missing or peg-shaped maxillary lateral incisors, rotations and malposition of the adjacent teeth, and retention of the deciduous canines are most often associated with transposition. In the maxilla the canine is transposed most frequently with the first premolar, less often with the lateral incisor followed rarely by central incisor or second premolar. In the mandible transposition is reported to involve the canine and lateral incisor commonly. Although the etiology of tooth transposition remains unclear, two principal theories of this anomaly have been proposed. One is migration of the tooth buds from the normal path during odontogenesis. The other is a genetic influence. The treatment of these patients frequently requires multidisciplinary treatment planning to achieve a long-term esthetic and functional result. ${ }^{5}$ This clinical report describes multidisciplinary approach in the management of a patient with hypodontia and transposed mandibular canines.

\section{CASE REPORT}

A 21 years old male patient reported to the College of Dental Surgery, Mangalore for seeking treatment of unpleasant smile and replacement of missing teeth (Fig. 1).

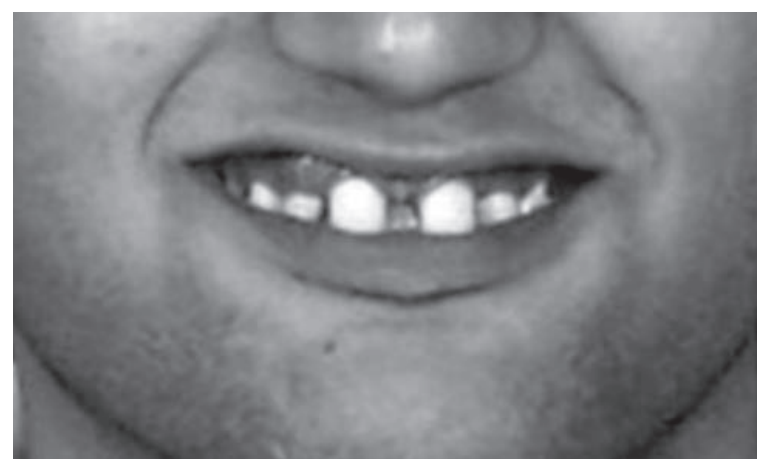

Fig:1 : Pre-treatment extra oral picture

The patient was in good general health, and the medical and dental history indicated no contraindications to dental treatment. Soft tissues were normal and other hard tissues were sound. The neighboring permanent teeth were caries-free without any signs of periodontal problems. Queries revealed that the retained deciduous teeth in the lower arch never got replaced. Intraoral examination revealed the missing laterals in the upper 


\section{ORTHODONTIC JOURNAL OF NEPAL}

arch, presence of midline diastema which is more than 6 $\mathrm{mm}$. Further, the patient had transposed lower canines, which are of slightly abnormal shape and occupied the position of mandibular central incisors. Retained deciduous teeth present in the lower arch are deciduous canines, and decidious lateral incisor on the right side (Fig. 3). Diagnostic records included orthopantomogram (OPG), lateral cephalogram and study models (Fig. 2) Undoubtedly, this is the case of upper/lower hypodontia with transposition of lower canines. Problem list consisted of multiple missing teeth, midline diestema of more than $6 \mathrm{~mm}$, upper anterior spacing due to missing upper laterals and transposed lower canines.
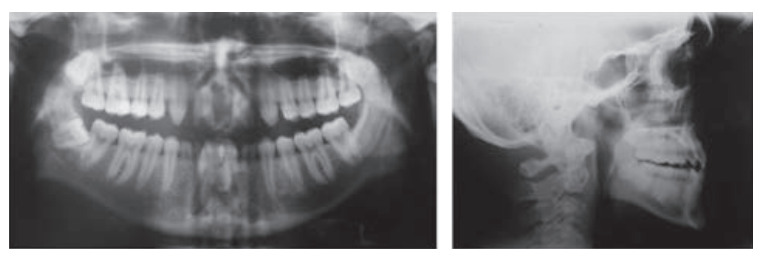

Fig:2 : Pre-treatment radiograph

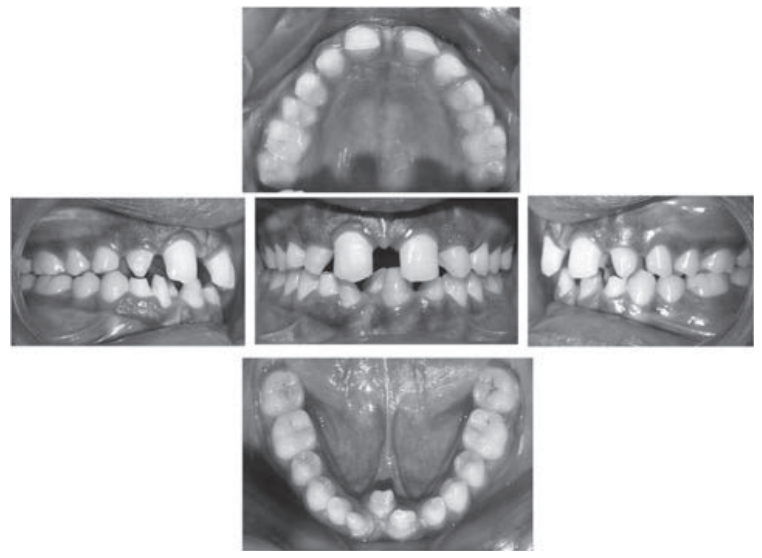

Fig: 3 : Pre-treatment intra oral picture

Treatment plan consisted of two phases. The first phase was orthodontic treatment with the objective to correct midline diastema, align transposed canines, improve incisor relationship and to improve lip support. Space created will be replaced with fixed partial dentures later in phase II. Phase II consisted of prosthetic rehabilitation for improving aesthetics and function. Mandibular deciduous incisors were not to be retained due to poor and unfavorable crown to root ratio. Porcelain fused to metal fixed partial denture (FPD), in two sections, both in maxillary and mandibular arches were planned.

Phase I therapy was initiated after extraction of retained deciduous teeth and oral prophylaxis. Pre-adjusted edgewise technique (0.022" Roth prescription) was used. Initial alignment was done using $0.016 \mathrm{NiTi}$ arch wires. 0.018 Australian stainless steel wire was used in upper arch along with open coil between central incisor and canine to mesialise the central incisors and to close the midline diastema. Similarly lower looped $0.017 \times 0.0$
25 SS arch wires was used to procline the lower right transposed canine and align the teeth in their transposed positions (which will be modified to incisors later in Phase II therapy) (Fig. 4). Mid treatment, OPG was taken to ascertain the parallelism of the roots. Lateral cephalogram showed improved relation of dentition to cranial base and to its basal bones. Lip position also showed improved results. After retaining the achieved results for three months, Phase II treatment was initiated (Fig. 5).

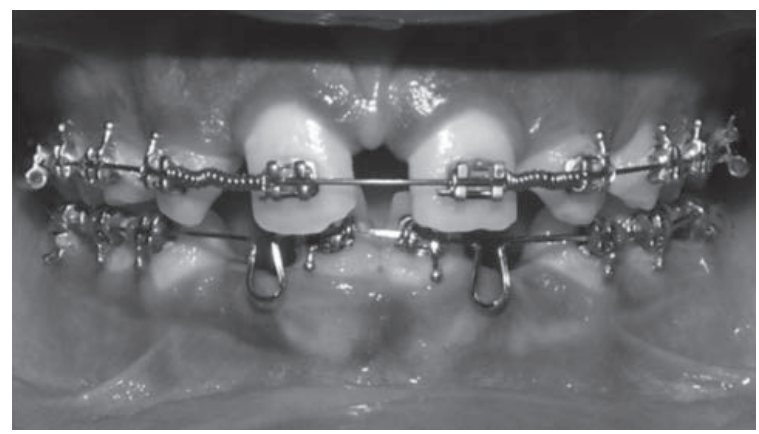

Fig: 4 : during treatment

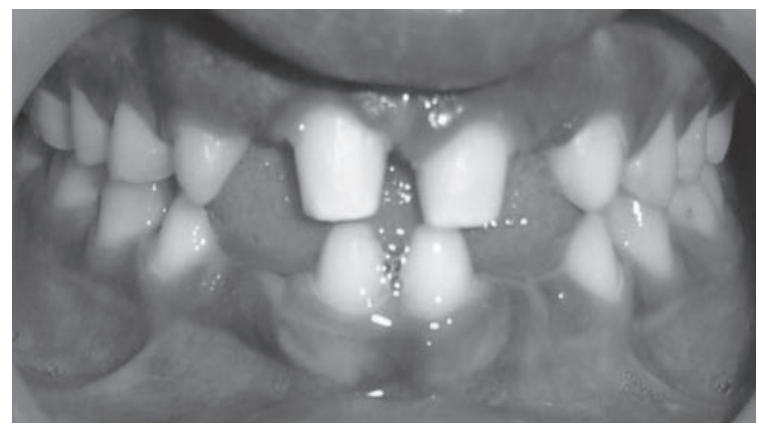

Fig : 5 : Prosthetic phase

Phase II therapy consisted of replacement of missing anterior teeth with fixed partial dentures (FPDs) to improve aesthetics and function. Irreversible hydrocolloid impression was made, diagnostic casts prepared and articulated in a semi-adjustable articulator (Whip - Mix Articulator) using facebow transfer (Quick Mount Facebow) and interocclusal records. To ensure a successful result, the prostheses were planned by waxing the intended restorations on articulated diagnostic casts. Maxillary canines and central incisors were prepared as abutments for FPDs. In the mandibular arch, transposed canines and first premolars were prepared as abutments for FPDs (Fig. 7). With special trays, impressions were made using additional silicone (polyvinyl siloxane) impression material and casts poured and articulated in the semi-adjustable articulator. Shade selection was done and the patient was sent back after cementing the provisional fixed partial dentures. In the subsequent appointments, metal try-in was carried out and FPD was placed onto the tooth abutments and evaluated for marginal integrity, occlusal relationships, and esthetic 
outcome. The prosthesis was cemented once found satisfactory. In the maxillary arch, two sets of three unit FPDs were cemented, whereas in the mandibular arch, two sets of four unit FPDs were cemented (Fig. 6 and Fig.7).

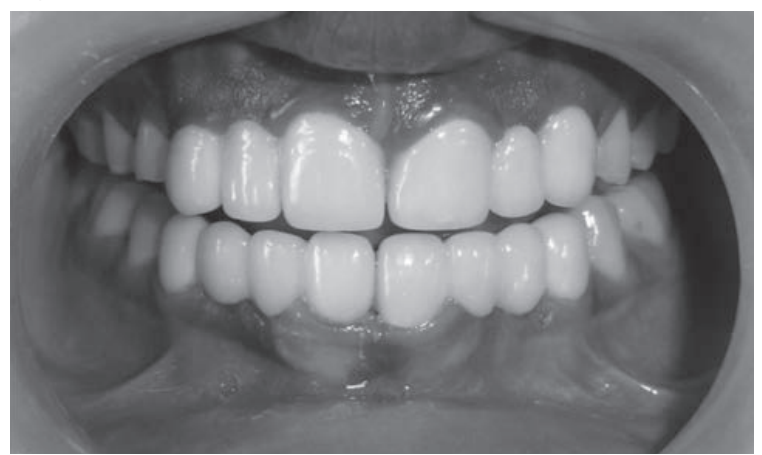

Fig: 6 : Postprosthetic intra oral picture.

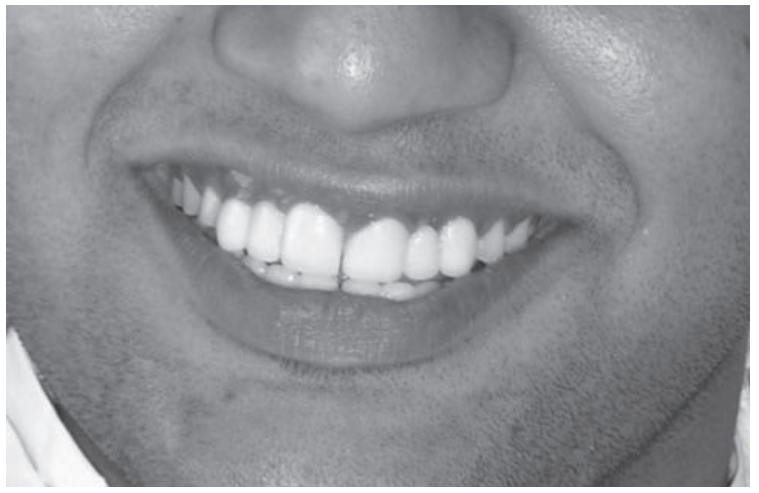

Fig:7 : Postprosthetic extra oral picture.

\section{DISCUSSION:}

Hypodontia is a condition for which patients require extensive and complex treatment, ranging from single restorations to surgery and multiple restorations, coupled with life-long maintenance. ${ }^{6}$ Treatment options for congenitally transposed and missing teeth were either to create space for the replacement of missing teeth, or to eliminate space and restoratively correct the tooth anatomy of the transposed and malformed teeth to provide acceptable esthetics. Orthodontic correction was carried out to close the diastema and to align the lower anterior. Midline diastema of more than $6 \mathrm{~mm}$ was noticed in this patient. Before formulating a definitive treatment plan for a patient with maxillary midline diastema, the clinician needs to understand the etiology of the condition. It can be an anomaly in the number of teeth (such as mesiodens or hypodontia) or the size of teeth (such as microdontia), an enlarged labial frenum, abnormal oral habits (such as tongue thrusting or nail biting) or advanced periodontitis. Clinicians must obtain a comprehensive medical history, including the duration of the diastema, any changes in size and any previous orthodontic treatment, as well as a comprehensive family history. Midline diastema in this case could be due to anomaly in the number of teeth, i.e. hypodontia. ${ }^{7}$ The relapse of the maxillary median diastema after orthodontic space closure, however, might be as great as $50 \%$. Sullivan et $\mathrm{al}^{8}$ found no predictors for relapse. Sashua and Artun $^{9}$ observed that the initial width of the diastema, a family member with diastema, and additional spaces between the maxillary anterior teeth are the most predictive factors of relapse. Permanent retention has been suggested to minimize relapse, FPDs cemented should retain the realigned maxillary arch.

Orthodontic correction in this case resulted in spaces for prosthodontic (FPD) replacement or implants. Since the pioneering work of Branemark, ${ }^{10}$ the use of osseointegrated implants to aid in restoring missing teeth has become the treatment of choice for patients with all forms of hypodontia. Although implant-supported prostheses may be considered as a treatment alternative where spaces have been created for the missing teeth, they are however expensive option to the patients. Owing to the higher expenditure, patient opted for same cheaper mode of restoration. The alternative treatment includes fixed partial dentures and a removable partial prosthesis. For many years, conventional fixed bridge work was considered to be the best treatment option for the replacement of a missing single tooth. The survival of this type of restorations was estimated to be about $75 \%$ after 15 years. Another option is a removable partial prosthesis. A common axiom in restorative dentistry is to use a fixed prosthesis whenever possible. The usual indication for removable option is the economics. ${ }^{11,12}$

Tooth preparation of the canines in the lower arch needs careful planning. Sufficient amount of tooth reduction is required so that the final prosthesis that would be cemented would simulate the lower central incisor along with the establishment of a normal overbite and overjet relationship. Therefore, a critical step in the treatment process is completion of a diagnostic wax-up. This enables the operator to evaluate the final occlusion, measure how much canine reduction is necessary, and determine whether an esthetic final result is achievable. Closure of midline diastema along with uprightment of lower right transposed canines, and alignment of upper and lower arch in general calls for the retainer which is sufficiently reliable as well as durable. The FPDs that we provided would restore the missing teeth as well as serve as an orthodontic retainers. Patient should be educated on the importance of oral hygiene maintenance for the long term success of the treatment.

\section{CONCLUSION:}

A close collaboration between the different dental fields plays the key role in diagnosis and treatment of these patients. While treating this case, initially orthodontic correction was carried out, followed by prosthodontic replacement of missing teeth with fixed partial dentures. A multidisciplinary treatment approach was selected to achieve optimal esthetic and functional results. 


\section{REFERENCES}

1. Arte S, Pirinen S. Hypodontia. Orphanet Encyclopedia 2004. Available at www.orpha.net/data/patho/GB/ uk - hypodontia.pdf (last accessed March 2012).

2. Polder BJ, Van't Hof MA, Van der Linden FP, Kuijpers - Jagtman AM. A meta-analysis of the prevalence of dental agenesis of permanent teeth. Community Dent Oral Epidemiol 2004; 32: 217 - 226.

3. Soames JV, Southam JC. Oral Pathology. $4^{\text {th }}$ ed. Oxford University Press; 2005.

4. Shapira Y, Kuftinec MM. Maxillary canine-lateral incisor transposition. Am J Ortho. 1989; 95: 5439-444.

5. Shapira Y, Kuftinec MM. A unique treatment approach for maxillary canine-lateral incisor transposition. Am J Orthod Dentofacial Orthop 2001; 119:540-5.

6. Hobkirk JA, Brook AH. The management of patients with severe hypodontia. J Oral Rehabil 1980; 7:289-98.

7. Chu CH, Zhang CF, Jin LJ. Treating a maxillary midline diastema in adult patients: A general dentist's perspective. J Am Dent Assoc. 2011;142:1258-64.

8. Sullivan TC, Turpin DL, Artun J. A postretention study of patients presenting with a maxillary median diastema. Angle Orthod. 1996; 66:131-8.

9. Shashua D, Artun J. Relapse after orthodontic correction of maxillary median diastema: A follow-up evaluation of consecutive cases. Angle Orthod. 1999; 69:257-63.

10. Branemark PI. Introduction to osseointegration. In: Branemark PI, Zarb GA, Alberktsson T, editors. Tissue-integrated prostheses. Chicago: Quitessence; 1985; 11-7.

11. Creugers NH, Käyser AF, van 't Hof MA. A meta-analysis of durability data on conventional fixed bridges. Community Dent Oral Epidemiol. 1994; 22:448-52.

12. Scurria MS, Bader JD, Shugars DA. Meta-analysis of fixed partial denture survival: Prostheses and abutments. J Prosthet Dent. 1998;79:459-64. 